NASA/TM-2004-212925

\title{
Overview of High Speed Close-Up Imaging in an Icing Environment
}

Dean R. Miller

Glenn Research Center, Cleveland, Ohio

Christopher J. Lynch and Peter A. Tate

InDyne, Inc., Cleveland, Ohio 
Since its founding, NASA has been dedicated to the advancement of aeronautics and space science. The NASA Scientific and Technical Information (STI) Program Office plays a key part in helping NASA maintain this important role.

The NASA STI Program Office is operated by Langley Research Center, the Lead Center for NASA's scientific and technical information. The NASA STI Program Office provides access to the NASA STI Database, the largest collection of aeronautical and space science STI in the world. The Program Office is also NASA's institutional mechanism for disseminating the results of its research and development activities. These results are published by NASA in the NASA STI Report Series, which includes the following report types:

- TECHNICAL PUBLICATION. Reports of completed research or a major significant phase of research that present the results of NASA programs and include extensive data or theoretical analysis. Includes compilations of significant scientific and technical data and information deemed to be of continuing reference value. NASA's counterpart of peerreviewed formal professional papers but has less stringent limitations on manuscript length and extent of graphic presentations.

- TECHNICAL MEMORANDUM. Scientific and technical findings that are preliminary or of specialized interest, e.g., quick release reports, working papers, and bibliographies that contain minimal annotation. Does not contain extensive analysis.

- CONTRACTOR REPORT. Scientific and technical findings by NASA-sponsored contractors and grantees.
- CONFERENCE PUBLICATION. Collected papers from scientific and technical conferences, symposia, seminars, or other meetings sponsored or cosponsored by NASA.

- SPECIAL PUBLICATION. Scientific, technical, or historical information from NASA programs, projects, and missions, often concerned with subjects having substantial public interest.

- TECHNICAL TRANSLATION. Englishlanguage translations of foreign scientific and technical material pertinent to NASA's mission.

Specialized services that complement the STI Program Office's diverse offerings include creating custom thesauri, building customized databases, organizing and publishing research results ... even providing videos.

For more information about the NASA STI Program Office, see the following:

- Access the NASA STI Program Home Page at http://www.sti.nasa.gov

- E-mail your question via the Internet to help@sti.nasa.gov

- Fax your question to the NASA Access Help Desk at 301-621-0134

- Telephone the NASA Access Help Desk at 301-621-0390

- Write to:

NASA Access Help Desk

NASA Center for AeroSpace Information 7121 Standard Drive

Hanover, MD 21076 
NASA/TM-2004-212925

\section{Overview of High Speed Close-Up Imaging in an Icing Environment}

Dean R. Miller

Glenn Research Center, Cleveland, Ohio

Christopher J. Lynch and Peter A. Tate

InDyne, Inc., Cleveland, Ohio

Prepared for the

42nd Aerospace Sciences Meeting and Exhibit

sponsored by the American Institute of Aeronautics and Astronautics

Reno, Nevada, January 5-8, 2004

National Aeronautics and

Space Administration

Glenn Research Center 


\section{Acknowledgments}

The authors would like to acknowledge and thank Mr. Gene Hill and Dr. James Riley, FAA, for their support of the experimental investigations on droplet splashing visualization conducted at the ACT icing wind tunnel, and also the visualization of mixed phase icing conditions conducted at the Cox \& Company LeClerc Icing

Research Laboratory.

Available from

NASA Center for Aerospace Information 7121 Standard Drive

Hanover, MD 21076
National Technical Information Service 5285 Port Royal Road Springfield, VA 22100

Available electronically at http:/ /gltrs.grc.nasa.gov 


\title{
OVERVIEW OF HIGH SPEED CLOSE-UP IMAGING IN AN ICING ENVIRONMENT
}

\author{
Dean R. Miller* \\ National Aeronautics and Space Administration \\ Glenn Research Center \\ Cleveland, Ohio 44135 \\ Christopher J. Lynch ${ }^{\dagger}$ and Peter A. Tate \\ InDyne, Inc. \\ Cleveland, Ohio 44135
}

\begin{abstract}
$\underline{\text { ABSTRACT }}$
The Icing Branch and Imaging Technology Center at NASA Glenn Research Center have recently been involved in several projects where high speed close-up imaging was used to investigate water droplet impact/ splash, and also ice particle impact/bounce in an icing wind tunnel. The combination of close-up and high speed imaging capabilities were required because the particles being studied were relatively small $(\mathrm{d}<1 \mathrm{~mm}$ in diameter), and the impact process occurred in a very short time period $\left(\mathrm{t}_{\text {impact }}<<1 \mathrm{sec}\right)$.

High speed close-up imaging was utilized to study the dynamics of droplet impact and splash in simulated Supercooled Large Droplet (SLD) icing conditions. The objective of this test was to evaluate the capability of a ultra high speed camera system to acquire quantitative information about the impact process (e.g., droplet size, velocity). Imaging data were obtained in an icing wind tunnel for spray cloud MVD > $50 \mu \mathrm{m}$.
\end{abstract}

High speed close-up imaging was also utilized to characterize the impact of ice particles on an airfoil with a thermally protected leading edge. The objective of this investigation was to determine whether ice particles tend to "stick" or "bounce" after impact. Imaging data were obtained for cases where the airfoil surface was heated and unheated. Based on the results from this test, follow on tests were conducted to investigate ice particle impact on the sensing elements of water content measurement devices.

This paper will describe the use of the imaging systems to support these experimental investigations, present some representative results, and summarize what was learned about the use of these systems in an icing environment.

\footnotetext{
*AIAA Member, Icing Research Engineer

${ }^{\dagger}$ Imaging Specialist
}

\section{NOMENCLATURE}

$\begin{array}{ll}\mathrm{d} & \begin{array}{l}\text { water droplet diameter }(\mu \mathrm{m}) \\ \text { field of view } \\ \text { splashing threshold parameter } \\ \mathrm{k}\end{array} \\ \mathrm{\text {non-dimensional) }} \\ \text { IPS } & \begin{array}{l}\text { ice protection system } \\ \text { liquid water content }\left(\mathrm{g} / \mathrm{m}^{3}\right)\end{array} \\ \mathrm{MVD} & \text { mean volumetric diameter }(\mu \mathrm{m}) \\ \mathrm{SLD} & \text { supercooled large droplet } \\ \mathrm{T}_{\text {total }} & \text { total temperature } \\ \mathrm{TWC} & \text { total water content }\left(\mathrm{g} / \mathrm{m}^{3}\right) \\ \mathrm{V} & \text { airspeed }(\mathrm{m} / \mathrm{sec})\end{array}$

\section{INTRODUCTION}

The use of high speed close-up imaging is not a new concept for icing. There have been previous uses by Olsen to look at the initial phases of ice accretion. ${ }^{1}$ Reehorst used close-up imaging to investigate ice feather growth rate in natural and simulated icing conditions. $^{2}$

More recently, the Icing Branch and Imaging Technology Center at NASA Glenn Research Center have been involved in projects where high speed closeup imaging techniques were required. This has led to the development and evaluation of imaging systems and methods to provide visual data which is complementary to other experimental measurements. This report is intended to provide an overview of the development and use of these imaging systems and methods in the following areas: (1) Large droplet impact and splash characterization, (2) Ice particle impact on a thermally protected surface, and (3) Ice particle impact on hotwire water content sensors.

For each area, a brief statement of the relevant technical issues will be provided first. Then the experimental investigation and imaging systems will be discussed, and followed by a presentation of representative 
imaging results. This report will conclude with a general discussion of what has been learned from the development and use of high speed close-up imaging methods in an icing environment.

\section{DISCUSSION AND RESULTS}

\section{Large Droplet Impact and Splash}

The investigation of water droplet impact has been driven by a desire to develop improved ice prediction computer programs which account for the splashing of Supercooled Large Droplets (SLD). It is known that larger water droplets have a tendency to splash more upon impact, than do smaller water droplets. Mundo et al. have proposed a dimensionless splashing parameter ( $\mathrm{k}$ factor) which has been correlated with observations of splash. ${ }^{3}$ They have defined a splashing threshold where splashing is expected to occur for values of $k>57$.

The potential mass loss associated with the splashing of large water droplets has implications for the ice accretion process. There is the possibility that splashed products are swept away from the surface by airflow over the surface (resulting in a mass loss), or that they re-impinge on the surface (causing a re-distribution of mass) at another location. These effects have the potential to affect the resultant ice accretion.

Given the current emphasis on upgrading existing ice prediction code capabilities to include SLD icing conditions (having large supercooled water drops $>50 \mu \mathrm{m}$ diameter), it will be necessary to incorporate the effects of splashing into the ice accretion physics models utilized in these codes. This improved capability will upgrade the ice prediction codes to support SLD icing certification activities. ${ }^{4}$

The dynamics of the splash process (incoming and splashed droplet size, velocity, and angle, and any resultant mass loss) will need to be quantified, to facilitate the development of these upgraded ice accretion models. Close-up high speed imaging will play a key role in acquiring the information and understanding of the splash process.

A preliminary investigation of high speed close-up imaging methods required to capture droplet splash characteristics was conducted in the Advanced Composite Technologies (ACT) icing wind tunnel in May 2002. This test was sponsored by the Federal Aviation Administration (FAA), and was jointly conducted by NASA Glenn Research Center and QinetiQ.
The objective of this test was to explore the capabilities of close-up ultra high speed imaging techniques in an optimum environment with a water spray having large droplets (droplet diameter $>50 \mu \mathrm{m}$ ) and answer the following questions: (1) can the droplet impact process be captured in a spray environment, and (2) is it possible to quantify the dynamics of the droplet impact process in a spray environment (i.e., track/characterize a single droplet as it approaches, impacts, and then track/characterize droplets that are splashed off).

Test Setup: This test was conducted in the small ACT test section having dimensions of 7 in. $(17.8 \mathrm{~cm})$ wide by 12 in. $(30.5 \mathrm{~cm})$ in height. This tunnel was chosen for this exploratory test based on the good visual access provided by the test section. We were able to get the lens of the high speed camera system within 6 in. $(15.2 \mathrm{~cm})$ of the point of interest on the test article.

Two test articles were selected for this test: A 2.5 in. $(6.35 \mathrm{~cm})$ chord symmetrical airfoil and a half round cylinder which are shown in figure 1.

The small airfoil was selected to image more direct droplet impacts at 75 and 90 degrees with respect to the impact surface, while the half-round was chosen for more shallow impacts of 15 degrees.

The majority of test points were obtained with the airfoil model, and so the discussion from this point on will be focused on this model. The airfoil model was horizontally mounted in the test section and used as a target for this droplet impact visualization study. A portion of the model leading edge $(10 \mathrm{~mm}$ about the highlight) was blunted to facilitate imaging of the droplet impact process. Figure 2 shows a close-up of the test section with the airfoil test article installed.

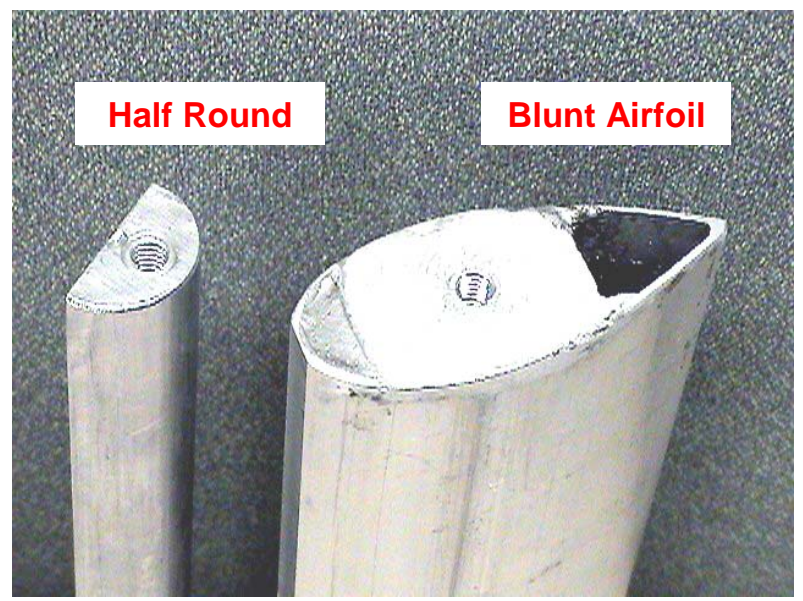

Figure 1. Test articles used for splashing visualization test. 


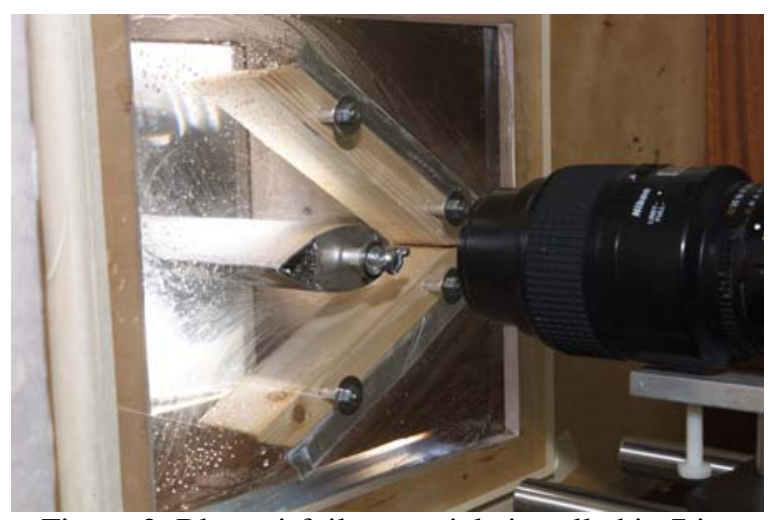

Figure 2. Blunt airfoil test article installed in 7 in. by $12 \mathrm{in.} \mathrm{ACT} \mathrm{icing} \mathrm{tunnel} \mathrm{test} \mathrm{section.}$

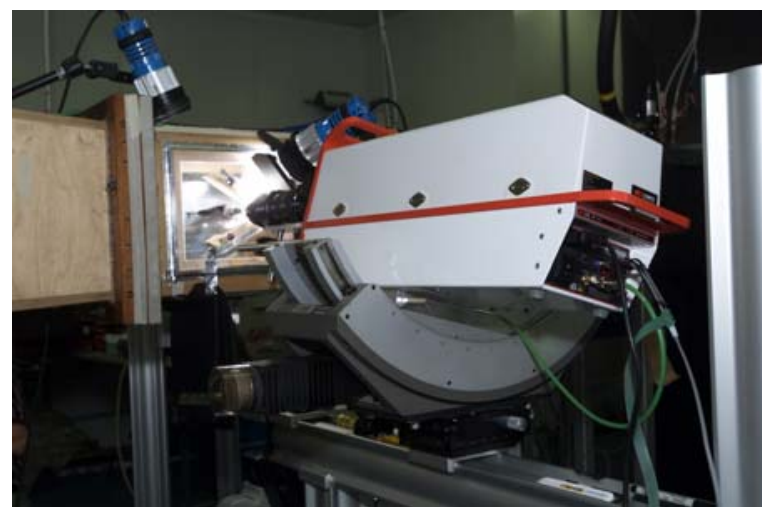

Figure 3. Ultra-8 high speed imaging system.

Imaging System: An Ultra-8 high speed imaging system (shown in fig. 3) was used to record the droplet impact process as a sequence of 8 images.

This camera system had previously found application in the area of high speed ballistics research, and its features are listed below:

- Gated high resolution image intensified high speed digital camera

- Captures 8 images at $520 \times 520$ pixel resolution - pixel size $14 \times 14 \mu \mathrm{m}$

- Programmable exposure and inter-frame times ranging from 10 nanoseconds to 1 millisecond

- Framing rate of 500 to 100 million frames/sec

- Software functions:

- calculate distance, velocity, and angle

- contrast adjustment on stored images

- create intensity profiles for single images

In addition to the Ultra-8 high speed imaging system, a high-definition video camera was also used to record the general characteristics of the spray conditions in the vicinity of the airfoil leading edge where the high speed close-up image sequences were obtained.

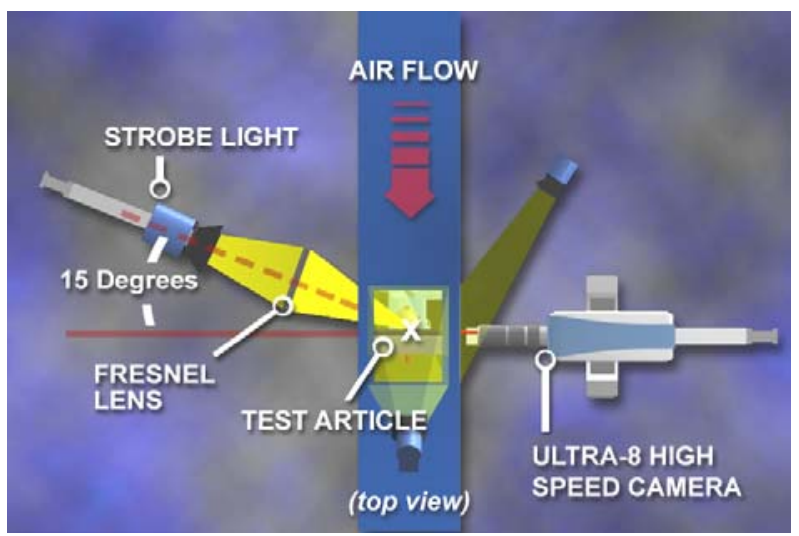

Figure 4. Top view of imaging setup at ACT icing tunnel.

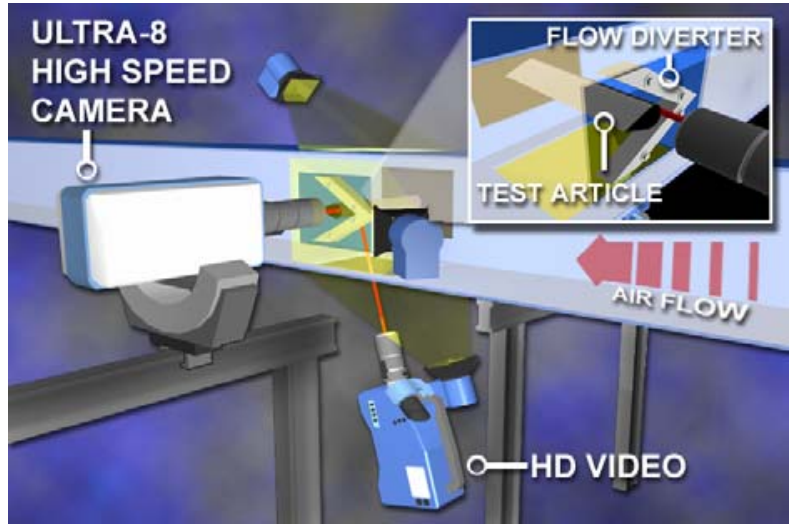

Figure 5. Side view of imaging setup at ACT icing tunnel.

Figures 4 and 5 show the overall setup of the imaging systems with respect to the test article and tunnel airflow direction.

Test Process: The ultra-high speed camera system was used to obtain close-up imagery of droplet splash for the range of conditions listed below.

- Velocity (25, 50, and $75 \mathrm{mps})$

- Drop size MVD (100 to $200 \mu \mathrm{m})$

- $\quad \operatorname{LWC}\left(0.3\right.$ to $\left.0.7 \mathrm{~g} / \mathrm{m}^{3}\right)$

- $\mathrm{T}_{\text {total }}\left(2\right.$ to $\left.20^{\circ} \mathrm{C}\right)$

- Impact angle wrt surface $(15,75$, and $90 \mathrm{deg})$

This experiment was conducted at above freezing tunnel temperatures. This was done to avoid any issues associated with supercooling of the spray cloud droplets, since the spray nozzles were only 1.6 meters upstream of the test section.

Imaging Issues: There were a number of issues faced in this experimental investigation. As one might expect, the most significant issue involved getting enough light on the subject. This was due to the fact that recording 
the features of the droplet impact and splash required very high frame rates (45 000 to 60000 frames/sec) and very short exposure times (35 ns).

The camera was positioned as close as possible to the tunnel side window, to minimize the required magnification. This resulted in an effective standoff distance of approximately $5.5 \mathrm{in}$. $(0.14 \mathrm{~m})$ between the front element of the camera lens and the imaging target area on the test article.

Because imaging was attempted in a spray environment, the cloud itself produced a very high level of reflected light (noise) which was undesirable. To mitigate this, a powerful electronic strobe (6400 watt-sec) and a fresnel lens $(254 \mathrm{~mm}$ focal length) were used to concentrate the light at the imaging target area on the test article. This approach created a point source of very intense light to illuminate splash events, essentially increasing the optical signal to noise ratio. We also found that orienting the strobe unit at 15 degrees with respect to the impact plane increased the illumination level for viewing the splash event (fig. 4).

Another significant issue, encountered during the course of testing, was the buildup of water droplets on the side viewing window of the test section. This buildup of water droplets obstructed a clear view of the imaging target area, which was at the spanwise centerline of the horizontally mounted test article. A wedge shaped flow diverter (fig. 2) was constructed to keep the water spray from impinging on the side window. It helped greatly, but did not altogether resolve this issue. Unfortunately, it was not until the very end of the test that a better solution than the flow diverter was conceived. This involved drilling a hole in the side window of the test section and then focusing the camera thru the hole.

Imaging Results: Images of large water droplet impact, were captured with the ultra-high speed camera system. A progression of 6 sequential images is shown in figure 6. This sequence shows the approach, and eventual impact with the surface of the blunt airfoil test article. The relatively high level of background noise is evident in this image sequence and was a factor which limited our ability to define the smaller features of the splash event. This background noise was believed to be due to the scattered light from the water droplets and the Ultra-8 image intensifier. For the optical setup employed in this test, the minimum resolvable droplet diameter was determined to be $100 \mu \mathrm{m}$.

The particle impact was captured, but the details of the splashed ejecta were not resolvable. Information about pre and post splash droplet size, velocity, and trajectory

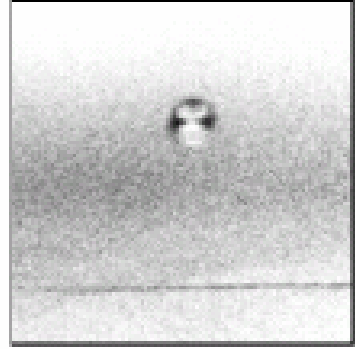

(a)

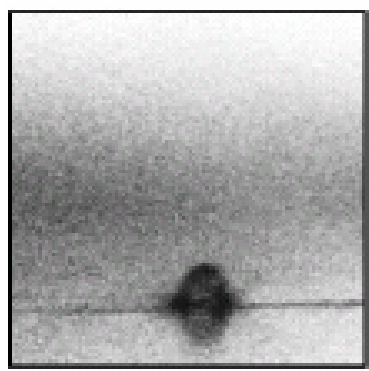

(c)

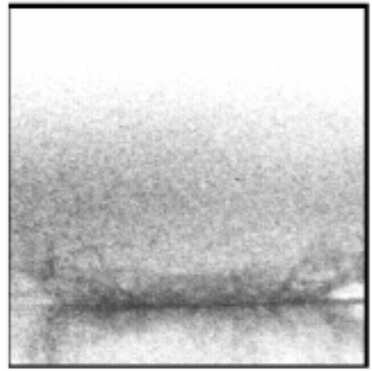

(e)

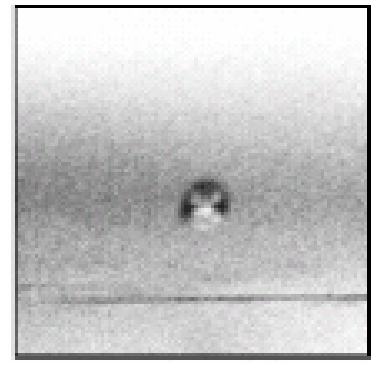

(b)

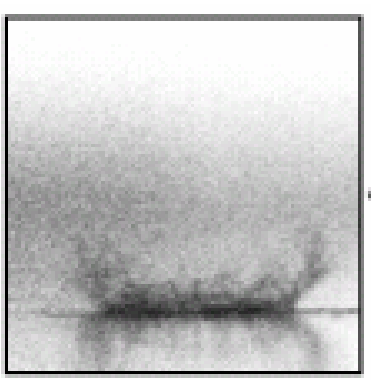

(d)

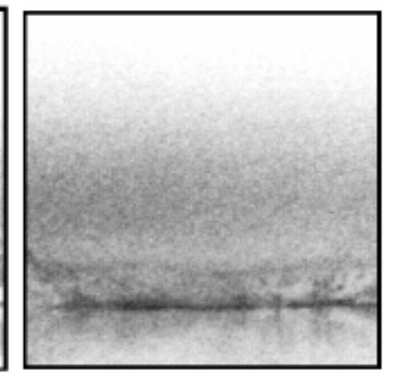

(f)
Figure 6. Ultra-high speed image sequence of a $540 \mu \mathrm{m}$ diameter droplet impact and splash $(\mathrm{V}=50 \mathrm{mps}$, $\mathrm{T}_{\text {tot }}=17{ }^{\circ} \mathrm{C}, \mathrm{LWC}=1.35 \mathrm{~g} / \mathrm{m}^{3}, \mathrm{FOV}=3.7 \mathrm{~mm}^{2}$, Exposure $=35$ ns, Frame Rate $=50000$ frames $/ \mathrm{sec}$, Gain = 3).

will be necessary to facilitate the development of water droplet splash models for ice prediction codes. It would be desirable to have sufficient resolution to allow the tracking of individual particles, to determine if ejecta re-impinge or are swept away by the air stream. Postprocessing individual images with particle tracking software may provide an option, assuming the optical signal to noise ratio could be improved by reducing the background noise in an image.

It was possible to quantify the incoming droplet diameter and velocity, as well as the splash height using calculation functions, which were native to the Ultra- 8 camera system. For the sequence shown above, the following measurements were made: 
- $\quad$ droplet diameter $=540 \mu \mathrm{m}$

- $\quad$ velocity $=35.29 \mathrm{~m} / \mathrm{s}$

- $\quad$ splash height $=960 \mu \mathrm{m}$

The difference between the measured drop velocity and the tunnel airspeed suggests that the larger droplets may not have fully accelerated to the tunnel airspeed of $50 \mathrm{mps}$ in the relatively short distance of 1.6 meters between the spray bar location and the test article.

This test demonstrated that it was possible to capture close-up (2.45 to $5.05 \mathrm{~mm}^{2}$ field of view) imagery of water droplet splash events, and to quantify the attributes of the incoming water droplet with an impinging water spray. Unfortunately, we were not able to resolve characteristics associated with the splashed ejecta due to high background noise in the images. Based on this, the Ultra-8 high speed camera and imaging methods employed in this test, might be better suited for imaging of single droplet impact and splash experiments using a mono-dispersed droplet generator. The use of the droplet generator should greatly reduce, if not eliminate, issues of background light scattering and obscuration of the tunnel side windows experienced in this test.

\section{Ice Particle Impact on a Thermally Protected Surface}

In addition to characterizing liquid phase particle impact, there was interest in studying what happens when ice particles impact an aircraft surface. It was desired to evaluate the effect of mixed phase icing conditions on thermal ice protection system power requirements, versus those for conditions having only supercooled liquid. Since additional heat is required to melt ice particles, it was desired to determine if mixed phase icing conditions might require more thermal power than liquid only conditions. In addition, there was interest in studying the degree to which ice particles "stick" or "bounce" upon impacting a surface.

A test to investigate these questions was conducted in the Cox and Company LeClerc Icing Research Laboratory wind tunnel (fig. 7). ${ }^{5}$ This test was sponsored by the FAA, and was a collaborative activity between Cox \& Company, NASA Glenn Research Center, and Wichita State University. A test article

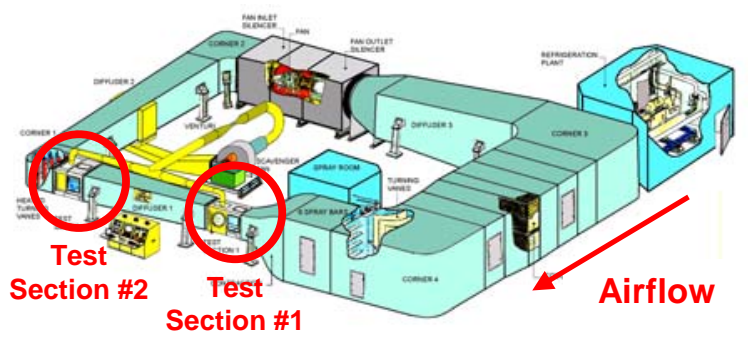

Figure 7. Cox \& Company icing wind tunnel. consisting of a 2-D wing section with an electrothermal ice protection system was tested under a variety of mixed phase conditions. NASA Glenn provided high speed close-up imaging systems for this test. The visual information obtained from the imaging systems was intended to complement thermal measurements from the test article. High speed close-up imaging methods were thus used to acquire a better understanding of the impact process, and the degree to which ice particles "stick" or "bounce" for particular mixed phase tunnel and test article surface conditions.

Test Setup: The test article chosen for this investigation consisted of a 3 foot $(0.91 \mathrm{~m})$ chord NACA-0012 airfoil section with a 7 zone electro-thermal ice protection system on the leading edge. The electro-thermal heater zones were equipped with temperature instrumentation, and were capable of being regulated to a set-point temperature, depending on the mode of operation. For a simulation of a running wet de-icing system, the surface temperature was maintained at a constant $50{ }^{\circ} \mathrm{F}$. To simulate fully evaporative operation, the surface temperature was maintained at $150{ }^{\circ} \mathrm{F}$. The airfoil was mounted horizontally in test section \#2 of the Cox \& Company icing wind tunnel, as shown in figure 8.

Imaging System: Three camera systems were used to visualize ice impact on the leading edge of the test article: (1) High speed camera, (2) High-definition Video camera, and (3) a mini-DV video camera.

A Phantom v5 high speed camera was selected for use in this test based on its ability to capture the short duration impact of ice particles, and facilitate playback as a "slowed down" video sequence for later analysis. This ability to generate slow motion movies was an extremely useful feature, in developing a qualitative understanding of the ice particle impact process. A Nikkor $200 \mathrm{~mm}$ lens was used with the camera for this test.

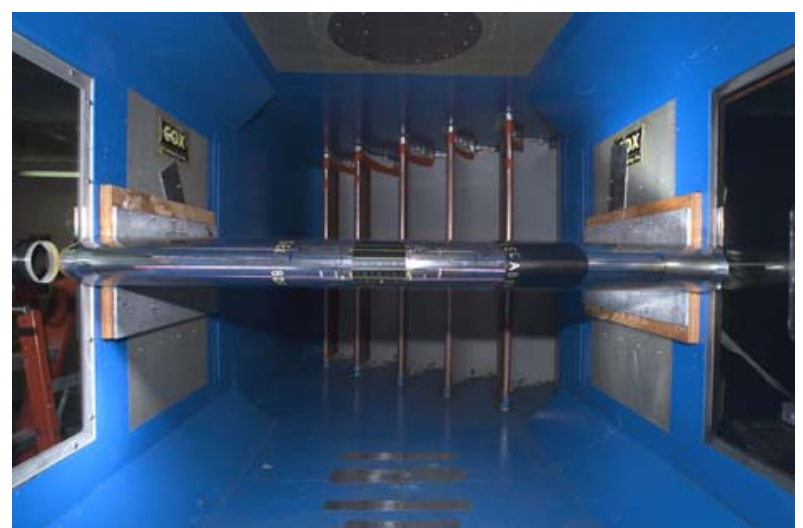

Figure 8. Electro-thermally heated test article mounted in the Cox \& Company icing wind tunnel. 
Other important technical capabilities of the Phantom v5 high speed camera are listed below:

- $10 \mu \mathrm{sec}$ exposure times

- 1000 frames/sec at $1024 \times 1024$ pixel resolution

- Measurement of linear displacement, and speed

- Post-processing imagery for brightness/ contrast, edge detection, sharpening, smoothing, and gamma correction

High-definition (HD) video was the second type of imaging system employed in this test. It was intended to provide highly resolved, real-time, close-up images of the test article leading edge, but at lower frame rates (60 frames/sec) than the high speed camera. This HD camera system utilized progressive scan with $1120 \times 720$ pixel resolution, and the CCD sensitivity was 1000 ISO. The lenses used in this test were Fujinon 17XHD (HA17x7.8BERM) zoom with max focal length of $150 \mathrm{~mm}$, and a Nikor $200 \mathrm{~mm}$ telephoto.

The third type of imaging system utilized in this test was a Mini-DV camera. It covered the widest FOV, and was intended to capture more of an overall view of what was happening on the airfoil leading edge. It was used to provide context to the close-up imagery from the high speed camera and HD video camera.

With the test article horizontally mounted in the tunnel, imaging of the leading edge area was best accomplished by either an overhead view, or from below. Since there was no visual access from above, a window in the floor of the test section was used to image the leading edge area of the airfoil (as shown in fig. 9). The cameras were tilted on a slight angle off vertical, and were approximately $30 \mathrm{in}$. $(0.76 \mathrm{~m})$ from the test article. Lighting of the test article was done using HMI lights thru both side windows in test section \#2.

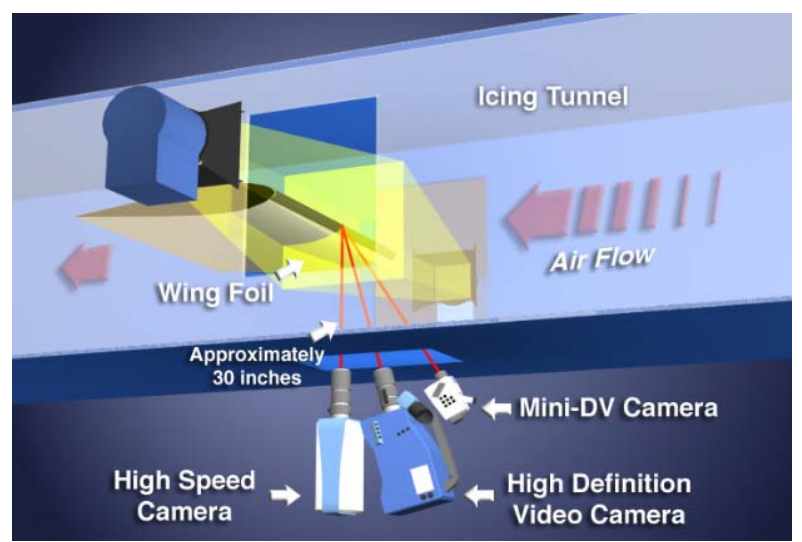

Figure 9. Orientation of three camera systems used to characterize the ice particle impact process.

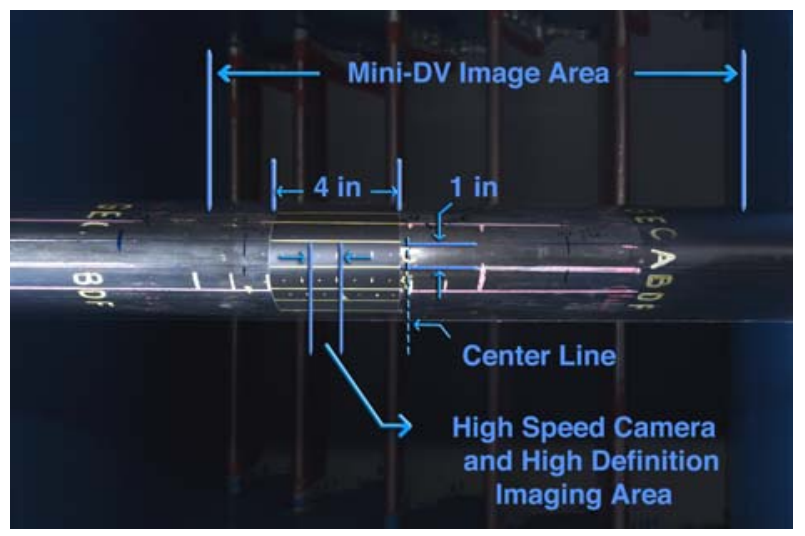

Figure 10. Close-up view of test article leading edge showing the imaging areas for the 3 camera systems.

The primary area of interest was a $1 \mathrm{in} .(2.5 \mathrm{~cm})$ square area located along the stagnation line of the airfoil, approximately $2.5 \mathrm{in}$. to the left of the tunnel centerline. Both the HD and high speed camera systems were focused within this area. The imaging locations were chosen near the horizontal centerline of the tunnel, to ensure that icing conditions would be as uniform as possible. The imaging areas for the 3 camera systems are shown in figure 10 .

Test Process: The objective of this test was to evaluate the effect of mixed phase icing conditions on the performance of a thermal ice protection system. To accomplish this, the test article was subjected to mixed phase icing conditions, which ranged from all supercooled water (100\% liquid), to a mixture of ice particles, to all ice particles (100\% ice). The specific mixed phase icing conditions used in this test are listed in table 1 .

For each of the conditions, the ice protection system was operated in the following 3 modes:

- $\quad$ no heat applied to the surface (IPS off)

- $\quad$ evaporative anti-icing mode $\left(\mathrm{T} \operatorname{surf}=150{ }^{\circ} \mathrm{F}\right)$

- $\quad$ wet anti-icing mode $\left(\operatorname{Tsurf}=50^{\circ} \mathrm{F}\right)$

Table 1. Range of mixed phase icing test conditions

\begin{tabular}{|c|c|c|c|}
\hline $\begin{array}{c}\mathbf{L W C}, \\
\left(\mathbf{g} / \mathbf{m}^{\mathbf{3}}\right)\end{array}$ & $\begin{array}{c}\text { IWC, } \\
\left(\mathbf{g} / \mathbf{m}^{\mathbf{3}}\right)\end{array}$ & $\begin{array}{c}\text { Ttot, } \\
\left({ }^{\circ} \mathbf{C}\right)\end{array}$ & $\begin{array}{c}\mathbf{V}, \\
(\mathbf{m p s})\end{array}$ \\
\hline 0.70 & 0 & -11.1 & 53.6 \\
\hline 0.35 & 0.35 & -11.1 & 53.6 \\
\hline 0 & 0.7 & -11.1 & 53.6 \\
\hline 0.70 & 0 & -17.8 & 53.6 \\
\hline 0.35 & 0.35 & -17.8 & 53.6 \\
\hline 0 & 0.7 & -17.8 & 53.6 \\
\hline
\end{tabular}


For those conditions where heat was applied to the IPS, the amount of power to maintain the surface temperature setpoint was recorded. This data was used to evaluate the relative impact of a particular mixed phase condition, on the IPS. Generally speaking, increased power requirements translated into a greater thermal load on the IPS

Imaging Issues: Overall, the imaging approach was straight forward, and there was good visual access. In a few cases, the viewing window became obscured with water droplets running over it, which impeded the view of the test article. It is believed that selection of a side viewing window (instead of a floor window) would have resolved this issue.

It was sometimes difficult to find the proper iris setting for the high-definition video camera, particularly when an ice accretion formed on the test article leading edge. The accretion caused more light to be reflected back to the camera, making it difficult to show the details of "bouncing" ice particles, and at the same time show the details of the water film on the iced surface. Typically, the iris setting was switched back and forth to allow non-simultaneous viewing of either ice bouncing from the surface, or iced surface details within a test run.

Imaging Results: Imaging results from the HD video and high speed camera systems yielded valuable qualitative information to complement the thermal measurements acquired from the ice protection system. One of the key questions posed prior to this test, was whether ice particles "stick" or "bounce" after impact with an aircraft surface. While quantitative values to answer this question were not obtained from the imaging data, it was possible to make some general statements relevant to this question.

"Bouncing" was observed frequently, whenever the icing tunnel spray cloud contained ice particles. The ice particles appeared to have ballistic trajectories after impact. Whether, the surface was wet or dry, ice particles were observed to impact the surface, shatter into smaller pieces, with those pieces subsequently being ejected into the air-stream or re-impinging on the airfoil surface. In some cases, the particles were observed to strike the surface at a very oblique angle, and be deflected off the surface directly into the airstream where they were swept away.

Not all of the impinging ice mass is believed to have "bounced" off the surface. Review of high-definition video for unheated surface conditions, revealed that after an ice particle impacted the surface and shattered, a piece of ice remained on the surface at the impact site. Eventually, it was observed to sublimate away. Some of the shattered fragments also re-impinged back on the surface, whereby they too eventually sublimated.
Figure 11 shows an ice particle impact and residual ice fragments on an unheated surface. No ice accumulation developed from the residual ice fragments that remained on the unheated surface.

For cases where the surface was heated, water beads were observed to form on the leading edge in the vicinity of the stagnation line. This was noted for all mixed phase spray conditions $(100 \%$ supercooled liquid, part liquid and ice, or $100 \%$ ice). The water beads then began to coalesce into larger beads and eventually ran back toward the trailing edge of the airfoil. Figure 12 is an example of imagery from the high-definition camera, showing water beads on the leading edge of the airfoil.

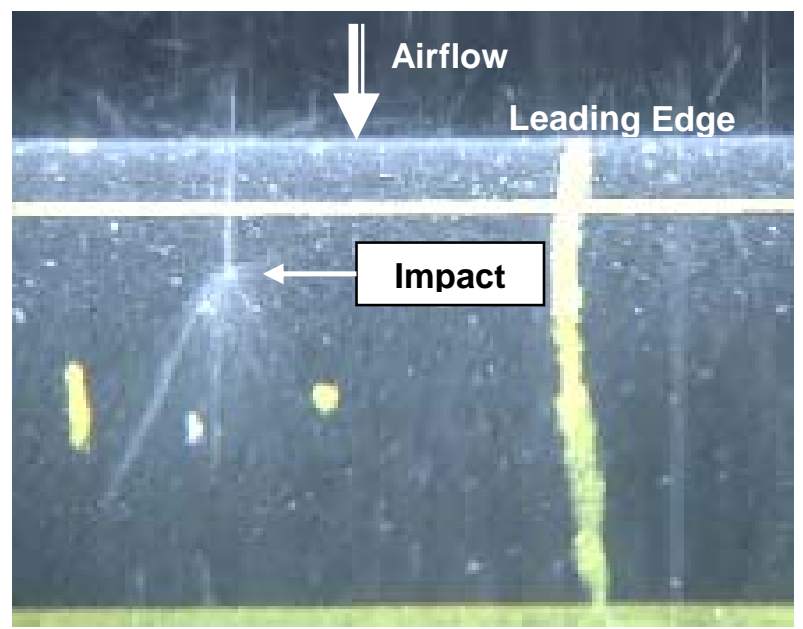

Figure 11. Frame capture image from high-definition video camera showing ice particle impact on an unheated surface. Residual pieces of ice on surface appear as specks of white against black airfoil surface.

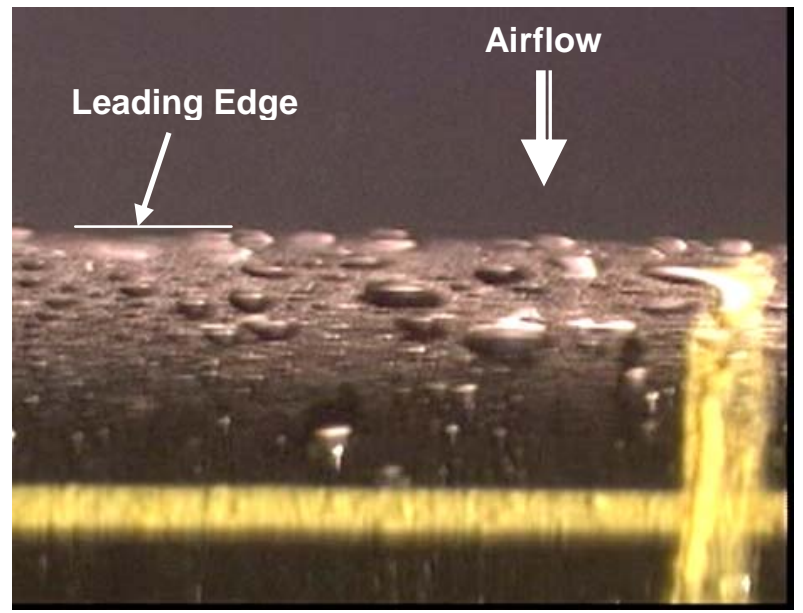

Figure 12. Frame capture image from high-definition video camera, showing water beads on the airfoil leading edge, with a heated surface. 
Though it was not possible to determine the exact percentage of total impinging ice mass which "bounced" or "stuck" for any given test condition, it was clear that some ice remained on the surface. This was indicated by an increase in the measured power to maintain a constant surface temperature for the 100 percent ice case, versus the measured power for dry conditions.

The high speed camera provided visual evidence that impinging ice particles may have actually splashed water off the IPS. Review of high speed imagery obtained during running-wet IPS operation, revealed that ice particles were impacting water beads, resulting in water being splashed away from the surface. The observation that splashing was occurring, provided a potential explanation for the lower power requirements in the heater areas aft of the stagnation line. In those areas, less power was required to maintain a constant surface temperature for mixed phase (liquid and ice) conditions, versus the power requirements for a supercooled spray ( $100 \%$ liquid). It is believed ice particles may have splashed water off the airfoil surface in these areas, essentially reducing the impinging total water content, and thus resulting in lower IPS thermal loads.

Ice Particle Impact on Water Content Sensors

The final application of high speed close-up imaging to be discussed in this paper concerns ice particle impact on hot-wire cloud water content sensors. During the mixed phase icing test, ice particles were observed to "bounce" off the test article surface. This was true for every simulated mixed phase icing condition where ice particles were introduced into the flow. This observation caused us to speculate on whether ice particles might also be "bouncing" upon impact with hot-wire Total Water Content (TWC) sensors, which have been assumed to capture and evaporate all impinging particles (whether ice or supercooled liquid).

To investigate this further, a test was conducted in the LeClerc Icing Research Laboratory wind tunnel in June 2003. Hotwire LWC and TWC probes were subjected to a range of icing conditions having both liquid and ice particles. The measurements from these instruments were then inter-compared with each other. As with the previous mixed phase test, high speed close-up imaging was used to study the impact of ice particles on the hotwire sensing elements of several probes. The test objectives were as follows:

- Determine if ice particles "bounce" off sensing elements of hot-wire probes

- If bouncing occurs, attempt to quantify the effect of bouncing on measured liquid water content
- Inter-compare the response of hot-wire probes subjected to mixed phase icing conditions in a controlled environment

Test Setup: Test section \#1 of the Cox and Company wind tunnel pictured in figure 7 , was used for this investigation. The smaller test section dimensions of 28 in. $(0.71 \mathrm{~m})$ wide by $46 \mathrm{in}$. high $(1.17 \mathrm{~m})$ afforded closer visual access, and higher airspeed than test section \#2 (used for the previously mentioned mixed phase investigation).

A special floor plate was fabricated for securing the hot-wire probe mounting stands to the floor of the tunnel. Mounting stands were fabricated for each hotwire probe, and these stands were in turn bolted to the special floor plate assembly. This floor plate/ mounting stand approach enabled the sensing element of each probe to be located at the vertical and horizontal center line of the tunnel. This was done to reduce experimental uncertainty by locating each instrument sensing element at the same physical location in 3-dimensional space.

Several different hotwire water content probes were evaluated for their response to ice particles: (1) Nevzorov TWC/LWC probe, (2) Science Engineering Associates TWC probe, and (3) King LWC probe.

The Nevzorov probe (fig. 14) has both a TWC sensor and an LWC sensor integrated into one vane. This feature enables it not only to measure the Total Water Content (Liquid + Ice), but to provide an estimate of Ice Water Content (IWC) in mixed phase conditions. Though water content measurements were recorded from both sensors, the imaging equipment was focused only on the conical TWC sensing element.

Another TWC probe developed by Science Engineering Associates (SEA) was evaluated, with the outside shroud removed. Normally this probe has an annular shroud surrounding the half-cylindrical shaped sensing element. However, the shroud was removed to facilitate lighting and viewing of the sense element for this test.

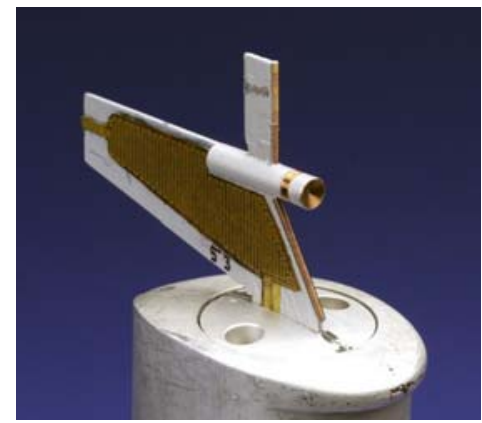

Figure 14. Nevzorov TWC/LWC probe. 


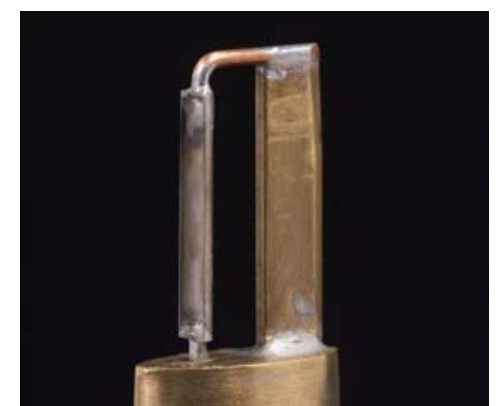

Figure 15. Science Engineering Assoc. TWC probe.

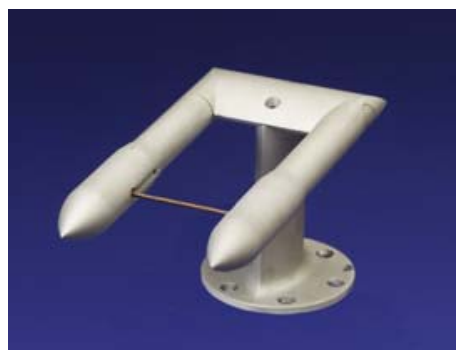

Figure 16. King LWC probe.

A King LWC probe was also evaluated for its response to ice particles. The imaging equipment was focused on the sensing wire, which extended between the two horizontal support arms. The King probe was included in this test because it has been used extensively over the years, resulting in a large database to characterize its performance. Therefore, it was thought that King probe results from this test might be able to be compared with this body of existing data for liquid and mixed phase conditions.

Imaging System: The cameras used in this test were the same as those used in the mixed-phase icing test discussed previously. A high-definition video camera, and a Phantom v5 high speed camera were used to visually study the impact of ice particles on the sensing element of the hot-wire cloud water content probes. The high-definition video camera was intended to provide a real-time high resolution record of each test run. The high speed camera was intended to capture ice particle impact at high frame rates, to facilitate later playback at reduced speeds. Imaging and lighting of the instruments under test were accomplished using the side windows of test section \#1. The imaging setup for this test is shown in figure 17.

Test Process: To evaluate the effect of ice particles on hot-wire probe measurements, the test article was subjected to a range of conditions including supercooled water (100\% liquid), a mixture of ice particles and liquid, and all ice particles (100\% ice). Water content measurements and close-up video of the probe sensing elements were acquired for each of these test conditions which are listed in table 2 .

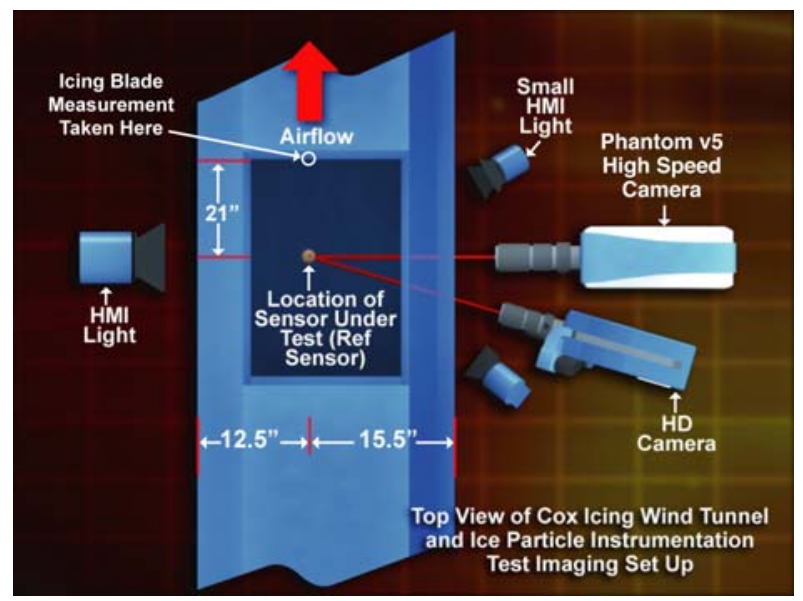

Figure 17. Imaging setup for investigation of ice particle impact on cloud water content instrumentation.

Table 2. Range of test conditions used to evaluate hot-wire probe response to ice particles.

Note: Supercooled water spray had $30 \mu \mathrm{m}$ MVD.

\begin{tabular}{|l|c|c|c|c|}
\hline $\begin{array}{c}\text { Condition } \\
\text { type }\end{array}$ & $\begin{array}{c}\mathbf{L W C} \\
\left(\mathbf{g} / \mathbf{m}^{3}\right)\end{array}$ & $\begin{array}{c}\text { Nominal } \\
\mathbf{I W C}, \\
\left(\mathbf{g} / \mathbf{m}^{3}\right)\end{array}$ & $\begin{array}{c}\text { Ttot, } \\
\left({ }^{\circ} \mathbf{C}\right)\end{array}$ & $\begin{array}{c}\mathbf{V}, \\
(\mathbf{m p s})\end{array}$ \\
\hline Spray 1 & 0.5 & -- & -12.2 & 67 \\
\hline Spray 2 & 0.75 & -- & -12.2 & 67 \\
\hline Spray 3 & 1.0 & -- & -12.2 & 67 \\
\hline Shaver 1 & -- & 0.2 & -12.2 & 67 \\
\hline Shaver 2 & -- & 0.4 & -12.2 & 67 \\
\hline Shaver 3 & -- & 0.6 & -12.2 & 67 \\
\hline Shaver 4 & & 0.9 & -12.2 & 67 \\
\hline Mixed & 0.5 & 0.6 & -12.2 & 67 \\
\hline
\end{tabular}

The supercooled water conditions were included to allow comparison with icing blade measurements. This provided a "baseline" measurement of probe performance relative to a reference measurement. Unfortunately, no such reference was available for the ice phase conditions.

Four "all ice" conditions were generated using the Cox \& Company's ice shaver system. The nominal measured ice water content associated with these simulated glaciated conditions is shown in table 2 . Though nominal IWC values are shown, the true value of IWC may have been higher, due to the effect of bouncing and a phenomena observed during this test which we labeled "pooling." There was also one mixed phase test condition comprised of supercooled spray, and ice shaver particles.

Imaging Results: As in the mixed phase icing test, the high-definition video and high speed camera yielded valuable qualitative information about the ice particle impact process. This imagery confirmed original conjectures that ice might be observed to "bounce" off the sensors, as well as revealing some unexpected results. 
Ice particles were observed to impact the hot-wire sensing element of the probes. In some cases the ice particles shattered into multiple smaller fragments, some of which rebounded off the sensor surface into the air-stream and were swept away. Also, a small residual piece of ice tended to remain on the surface of the sensing element after impact, until it apparently sublimated or melted. In other cases, the ice particle impact was observed to splash liquid off the sensing element and into the air-stream where it was swept away. Typical high-frame rate camera imagery of ice particle impacts are shown in figures 18 and 19 for the SEA TWC sensor, and the King probe sense wire, respectively.

One unexpected result, was a phenomena we called "pooling." It was first noticed occurring on the Nevzorov TWC sensor, and post-test review of high speed camera imagery suggests it may also be occurring on the SEA TWC sensor (to some degree). This

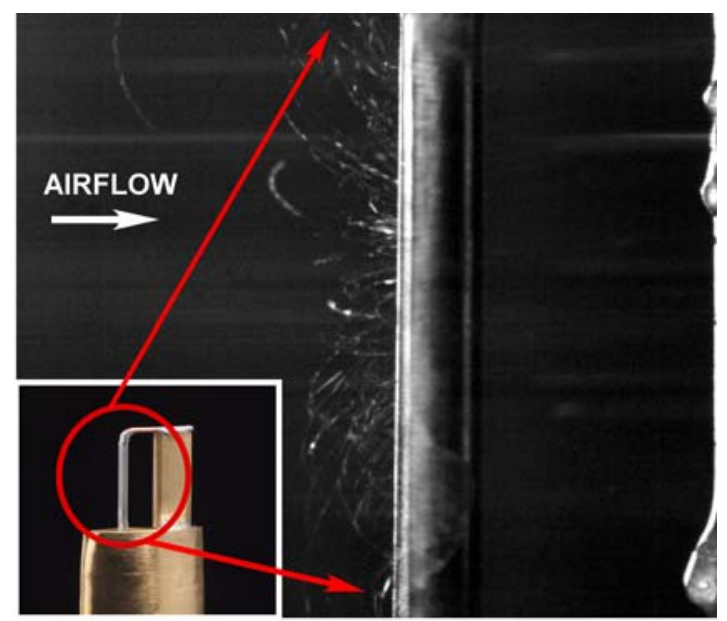

Figure 18. Ice particle impact on Science Engineering Associates TWC hot-wire sensing element (half-cylinder cross section).

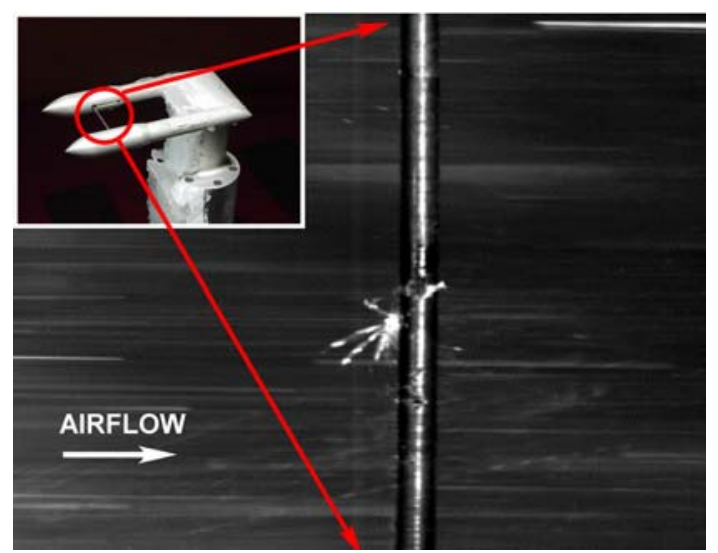

Figure 19. Ice particle impact on King probe hot-wire sensing element (cylindrical cross section).

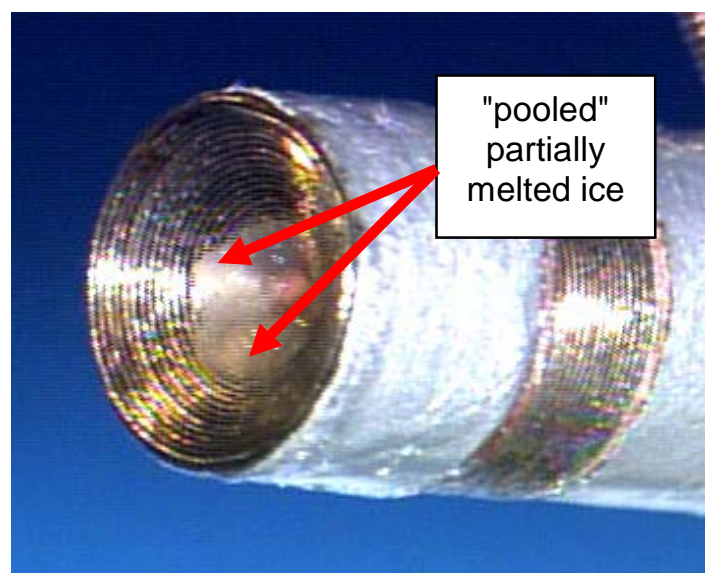

Figure 20. Close-up of Nevzorov TWC hot-wire sensing element showing melted ice particles.

phenomenon was manifest as a buildup of what appeared to be a slushy "pooled" mass of partially melted ice particles, as shown in figure 20. This mass appeared to grow in size, and at some point was eventually ejected from the sensing cone element, whereupon the cycle would start again. It was not known if this was an artifact of the test condition (i.e., choice of relatively high IWC levels compared to what exists in natural conditions).

Review of high-definition video imagery suggests this may not occur at lower levels of IWC. Future tests will explore this in more detail, and the high frame-rate camera and high-definition video are tools which are expected to play an important role in future testing of this nature.

\section{SUMMARY AND CONCLUSIONS}

The use of high speed close-up imaging has been discussed for three distinct experimental applications.

An ultra high speed camera system was evaluated for use in characterizing the attributes of large droplet impact and splash in an icing tunnel spray cloud. The results of this evaluation indicated that the ultra high speed camera system may be better suited for use in single droplet impact/splash experiments than in an icing tunnel spray. The high level of background noise induced by the scattered light from icing cloud droplets limited the ability to resolve and quantify the droplet impact/splash event to the degree desired.

A high speed camera system and high-definition video were used to investigate ice particle impact on a simulated thermal ice protection system. These cameras revealed that bouncing of ice particles (or fragments) was observed whenever ice particles were present (regardless of the surface condition: unheated, running 
wet, or evaporative). High speed imagery also suggested that impinging ice particles might also be splashing water from the surface upon impact. This observation correlated with reduced thermal power measurements for regions aft of the test article leading edge. In these regions, ice particles were believed to impact the test article surface at very shallow angles of incidence.

The high speed camera and high-definition video camera was also used to study ice particle impact on hot-wire cloud water content instrumentation. Ice particle impact/"bounce" was confirmed, but it was not possible to quantify the effect of the reduction in indicated IWC due to bouncing. Pooling of partially melted ice particles was identified to occur in the Nevzorov TWC sensor cone, and future testing at lower IWC is planned to investigate this further.

In all three applications, the imaging equipment provided qualitative visual information which facilitated a better understanding of the physical processes being studied. The use of these imaging tools in conjunction with quantitative measurements from instrumentation yielded a very comprehensive dataset. Therefore, we anticipate the continued use and development of high speed close-up imaging methods, as we strive to develop a better understanding of the physical mechanisms inherent in the ice accretion process.

\section{REFERENCES}

1. Olsen, W., Walker, E., Experimental Evidence for Modifying the Current Physical Model for Ice Accretion on Aircraft Surfaces, NASA TM-87184.

2. Reehorst, A., Ratvasky, T., Sims, J., Close-up Analysis of Inflight Ice Accretion, 32nd AIAA Aerospace Sciences Meeting and Exhibit, Jan. 1994, AIAA 94-0804.

3. Mundo, Chr, Sommerfeld, M., Tropea, C., DropletWall Collisions: Experimental Studies of the Deformation and Breakup Process, Int. J. Multiphase Flow, Vol. 21, No. 2, pp. 151-173, 1995.

4. Miller, D., Potapczuk, M., Bond, T., Update on SLD Engineering Tools Development, FAA International In-Flight Icing Conference, June 2003, SAE 2003-01-2127.

5. Al-Khalil, K., Irani, E., Miller, D., Mixed Phase Icing Simulation and Testing at the Cox Icing Wind Tunnel, 41st AIAA Aerospace Sciences Meeting and Exhibit, Jan. 2003, AIAA 2003-0903. 
Public reporting burden for this collection of information is estimated to average 1 hour per response, including the time for reviewing instructions, searching existing data sources, gathering and maintaining the data needed, and completing and reviewing the collection of information. Send comments regarding this burden estimate or any other aspect of this collection of information, including suggestions for reducing this burden, to Washington Headquarters Services, Directorate for Information Operations and Reports, 1215 Jefferson Davis Highway, Suite 1204, Arlington, VA 22202-4302, and to the Office of Management and Budget, Paperwork Reduction Project (0704-0188), Washington, DC 20503.

\begin{tabular}{|l|c|c|}
\hline 1. AGENCY USE ONLY (Leave blank) & $\begin{array}{c}\text { 2. REPORT DATE } \\
\text { February } 2004\end{array}$ & $\begin{array}{r}\text { 3. REPORT TYPE AND DATES COVERED } \\
\text { Technical Memorandum }\end{array}$
\end{tabular}

\section{TITLE AND SUBTITLE}

Overview of High Speed Close-Up Imaging in an Icing Environment

\section{6. $\operatorname{AUTHOR(S)}$}

Dean R. Miller, Christopher J. Lynch, and Peter A. Tate

\section{FUNDING NUMBERS}

WBS-22-728-41-01

8. PERFORMING ORGANIZATION REPORT NUMBER

E-14357

National Aeronautics and Space Administration

John H. Glenn Research Center at Lewis Field

Cleveland, Ohio 44135-3191

10. SPONSORING/MONITORING AGENCY REPORT NUMBER

National Aeronautics and Space Administration

Washington, DC 20546-0001

NASA TM-2004-212925

AIAA-2004-0407

\section{SUPPLEMENTARY NOTES}

Prepared for the 42nd Aerospace Sciences Meeting and Exhibit sponsored by the American Institute of Aeronautics and Astronautics, Reno, Nevada, January 5-8, 2004. Dean R. Miller, NASA Glenn Research Center; and Christopher J. Lynch and Peter A. Tate, InDyne, Inc., Cleveland, Ohio 44135. Responsible person, Dean R. Miller, organization code 5840, 216-433-5349.

Unclassified - Unlimited

Subject Category: 03

Distribution: Nonstandard

Available electronically at http://gltrs.grc.nasa.gov

This publication is available from the NASA Center for AeroSpace Information, 301-621-0390.

\section{ABSTRACT (Maximum 200 words)}

The Icing Branch and Imaging Technology Center at NASA Glenn Research Center have recently been involved in several projects where high speed close-up imaging was used to investigate water droplet impact/splash, and also ice particle impact/bounce in an icing wind tunnel. The combination of close-up and high speed imaging capabilities were required because the particles being studied were relatively small $\left(\mathrm{d}<1 \mathrm{~mm}\right.$ in diameter), and the impact process occurred in a very short time period $\left(\mathrm{t}_{\text {impact }}<<1 \mathrm{sec}\right)$. High speed close-up imaging was utilized to study the dynamics of droplet impact and splash in simulated Supercooled Large Droplet (SLD) icing conditions. The objective of this test was to evaluate the capability of a ultra high speed camera system to acquire quantitative information about the impact process (e.g., droplet size, velocity). Imaging data were obtained in an icing wind tunnel for spray cloud MVD $>50 \mu \mathrm{m}$. High speed close-up imaging was also utilized to characterize the impact of ice particles on an airfoil with a thermally protected leading edge. The objective of this investigation was to determine whether ice particles tend to "stick" or "bounce" after impact. Imaging data were obtained for cases where the airfoil surface was heated and unheated. Based on the results from this test, follow on tests were conducted to investigate ice particle impact on the sensing elements of water content measurement devices. This paper will describe the use of the imaging systems to support these experimental investigations, present some representative results, and summarize what was learned about the use of these systems in an icing environment.

\section{SUBJECT TERMS}

High-speed imaging; Aircraft icing; Aircraft safety; SLD (Supercooled Large Droplet)

\begin{tabular}{|c|c|c|}
\hline $\begin{array}{c}\text { 17. SECURITY CLASSIFICATION } \\
\text { OF REPORT } \\
\text { Unclassified }\end{array}$ & $\begin{array}{c}\text { 18. SECURITY CLASSIFICATION } \\
\text { OF THIS PAGE } \\
\text { Unclassified }\end{array}$ & $\begin{array}{c}\text { 19. SECURITY CLASSIFICATION } \\
\text { OF ABSTRACT } \\
\text { Unclassified }\end{array}$ \\
\hline
\end{tabular}

15. NUMBER OF PAGES 17 16. PRICE CODE 20. LIMITATION OF ABSTRACT 